\title{
Induction of Xanthine Dehydrogenase by TCDD
}

\author{
Kazumi Sugihara, ${ }^{* a}$ Kazuhiro Shimomiya, ${ }^{a}$ Shigeyuki Kitamura, ${ }^{a}$ \\ Shigeru Ohta, ${ }^{a}$ Keisuke Yamashita, ${ }^{b}$ and Mineo Yasuda ${ }^{b}$ \\ Institute of Pharmaceutical Science and Department of Anatomy, ${ }^{b}$ Hiroshima University \\ School of Medicine, 1-2-3 Kasumi, Minami-ku, Hiroshima 734-8551, Japan
}

\section{Introduction}

2,3,7,8-Tetrachlorodibenzo-p-dioxin (TCDD) is considered to be the most toxic of the chlorinated dioxin isomers that have been studied, and it has been comprehensively examined for its toxicological effects. Exposure to TCDD results in a number of toxic responses including carcinogenesis, teratogenesis, a wasting syndrome, immunotoxic effects and reproductive toxicity. ${ }^{1)}$ TCDD also causes the induction of enzymes including uridine $5^{\prime}$-diphosphate (UDP)-glucuronosyltransferase, DT-diaphorase and specific forms of cytochrome P450. ${ }^{2)}$ The induction has been proposed to result from binding of TCDD to the arylhydrocarbon receptor ( $\mathrm{AhR}$ ) protein, which is present in target tissues. The present study examined the inducibility of mouse liver enzymes by TCDD focusing on the cytosolic enzymes.

\section{Methods}

Male C57BL/6J mice were treated by gavage with a single dose of $40 \mu \mathrm{g} \mathrm{TCDD} / \mathrm{kg}$ body weight. Animals were killed $3 \mathrm{~d}$, and 1, 2 and 4 weeks after the dose. The liver microsomes and cytosol were prepared according to the usual method. The ethoxyresorufin- $O$-dealkylase (EROD), methoxyresorufin- $O$-dealkylase (MROD) and penthoxyresorufin- $O$-dealkylase (PROD) activities in liver microsomes were assayed by a fluorophotometrical method. Xanthine dehydrogenase $(\mathrm{XDH})$ and xanthine oxidase (XO) activities in liver cytosol were measured by the oxidation of 1-methylxanthine to 1methyluric acid with or without $\mathrm{NAD}^{+}$using HPLC. Aldehyde oxidase (AO) activity in liver cytosol was spectrophotometrically assayed by the oxidation of benzaldehyde. ${ }^{3)}$

\section{Results and Discussion}

When TCDD was given orally to mice, the EROD and MROD activities in liver microsomes after $3 \mathrm{~d}$ were induced 13- and 8-fold compared to the control mice dose with vehicle only, respectively. These activities were slightly decreased after 4 weeks. On the contrary, the microsomal PROD activity was not enhanced by treatment with TCDD. Administration of TCDD to mice also increased the cytosolic activities of $\mathrm{XO}$ and $\mathrm{XDH} 1.5-2.8$ times more than the control after 3 $\mathrm{d}$. These induced activities were maintained for 4 weeks after the dose. Enhanced activity for AO, which is a molybdenum-containing flavoenzyme and very closely related to $\mathrm{XO}$ and $\mathrm{XDH}$, was not observed in the mice treated with TCDD.

This study demonstrated for the first time that XO and XDH in liver cytosol of mice were induced by TCDD. The system composed with $\mathrm{XO}$ and $\mathrm{XDH}$ catalyzes the sequential conversion of hypoxanthine to uric acid. A by-product of the action of $\mathrm{XO} / \mathrm{XDH}$ is active oxygen, which has been implicated in a broad spectrum of pathologies. The induction of these enzymes by TCDD may be related to the various toxicities of TCDD.

\section{References}

1) Poland A., Knutson J.C., Annu. Rev. Pharmacol. Toxicol., 22, 517-524 (1982).

2) Kociba R.J., Schwetz B.A., Drug Metab. Reviews, 13, 387-406 (1982).

3) Johns D.G., J. Clin. Invest., 46, 1492-1505 (1967). 